Supporting Information for

\title{
The Role of Hydrogen Bonding in Preferential Solvation of 5-Aminoquinoline in Binary Solvent Mixtures
}

Sharmistha Das, Prajit Kumar Singha, Avinash Kumar Singh, Anindya Datta*

Department of Chemistry,

Indian Institute of Technology Bombay

Mumbai 400076, India

e-mail: anindya@ chem.iitb.ac.in (AD) Phone: +91 22 2576 7149, Fax: +91 2225767152 
Table of Contents

\begin{tabular}{|c|c|c|c|}
\hline S. No. & Content & Description & Page \\
\hline 1. & ote SN1 & rations of polar component in Figure 1 & S3 \\
\hline 2. & gure $S 1$ & Emission spectra maxima and FWHM variation with $x_{p}$ & S3 \\
\hline 3. & ble ST1 & Kamlet-Taft parameters of the solvents used & S4 \\
\hline 4. & Note SN2 & $\begin{array}{l}\text { Bagchi and Chatterjee Model for estimation of local mole } \\
\text { fraction. }\end{array}$ & S4 \\
\hline 5. & Table ST2 & $\begin{array}{l}\text { Local mole fractions } x_{p}^{L} \text { and deviation from bulk mole } \\
\text { fractions } \delta_{p} \text { for DEE-ACN/MeOH solvent mixtures }\end{array}$ & S5 \\
\hline 6. & Table ST3 & $\begin{array}{l}\text { Local mole fractions } x_{p}^{L} \text { and deviation from bulk mole } \\
\text { fractions } \delta_{p} \text { for Hexane-EtOH/tBuOH solvent mixtures }\end{array}$ & S5 \\
\hline 7. & Figu & $\begin{array}{l}\text { Preferential Solvation from calculated vs experimental } \\
\text { emission maxima }\end{array}$ & S6 \\
\hline 8. & ure S3 & Bi-component emission spectra fitting & S7 \\
\hline 9. & Table ST4 & $\begin{array}{l}\text { Fitting parameters for emission spectra of } 5 \mathrm{AQ} \text { in DEE- } \\
\text { ACN and DEE-MeOH solvent mixtures }\end{array}$ & S7 \\
\hline 10. & Figure S4 & Wavelength dependence of fluorescence transients & S8 \\
\hline 11. & Table ST5 & f $5 \mathrm{AQ}$ in $\mathrm{V}$ & S8 \\
\hline 12. & Table ST6 & $\begin{array}{l}\text { Fitting parameters for TCSPC transients of } 5 \mathrm{AQ} \text { in various } \\
\text { composition of DEE-MeOH solvent mixture }\end{array}$ & S9 \\
\hline 13. & Figure S5 & Rise time observed at red end of TCSPC transients & S9 \\
\hline 14. & Note $\mathrm{SN} 3$ & Estimation of translational diffusion timescales & S10 \\
\hline 15. & Table ST7 & $\begin{array}{l}\text { Calculated translational diffusion times in various } \\
\text { concentration of DEE-MeOH solvent mixture. }\end{array}$ & 10 \\
\hline 16. & Figure S6 & Time resolved emission spectra (TRES) & S12 \\
\hline 17. & Figure S7 & Time resolved area normalised emission spectra (TRANES) & S13 \\
\hline 18. & Figure S8 & $\mathrm{C}(\mathrm{t})$ and $\mathrm{FWHM}$ Variation & S14 \\
\hline 19. & Figure S9 & TRANES analysis & S15 \\
\hline
\end{tabular}




\section{Note SN1: Concentrations of polar component in Figure 1.}

(The following are listed in decreasing order of fluorescence intensity in Figure 1)

Figure 1A (concentration of ACN \%v/v): 0, 0.1, 0.2, 0.5, 1.0, 1.5, 2.5, 3.0, 3.5, 4.0, 4.5, 5.0, $25.0,50.0,75.0,100.0$.

Figure 1B (concentration of $\mathrm{MeOH} \% \mathrm{v} / \mathrm{v})$ : 0, 0.1, 0.2, 0.3, 0.5, 1.0, 2.0, 3.0, 4.0, 5.0, 10.0 .

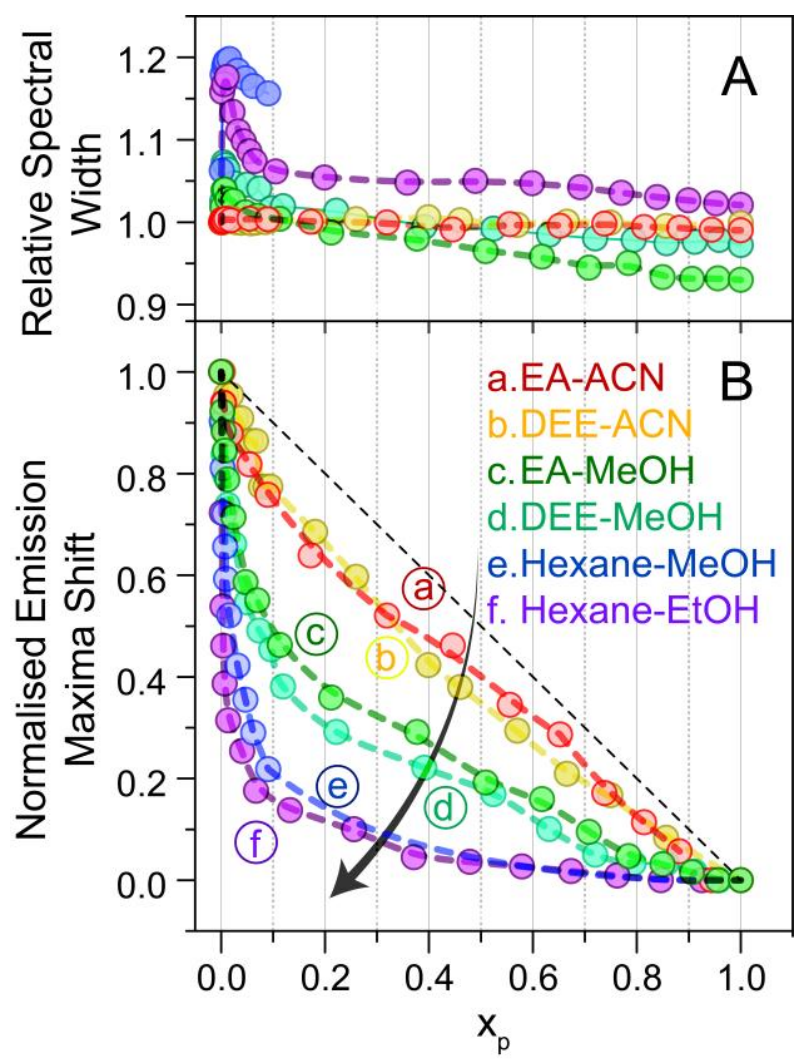

Figure S1. Variation of emission spectral maxima and FWHM with $x_{p}$. Variation of A) emission spectral bandwidth and B) emission spectral maxima with increasing polar component mole fraction $x_{p}$ in various solvent mixtures as indicated. 
Table ST1. Kamlet Taft Parameters of solvent components used.

\begin{tabular}{|c|c|c|c|}
\hline Solvent & $\boldsymbol{\pi}^{*}$ & $\boldsymbol{\beta}$ & $\alpha$ \\
\hline Hexane & -0.08 & 0 & 0 \\
\hline Diethyl Ether & 0.27 & 0.47 & 0 \\
\hline Ethylacetate & 0.55 & 0.45 & 0 \\
\hline t-Butanol & 0.41 & 1.01 & 0.68 \\
\hline Ethanol & 0.54 & 0.77 & 0.83 \\
\hline Acetonitrile & 0.75 & 0.31 & 0.19 \\
\hline Methanol & 0.60 & 0.62 & 0.93 \\
\hline \multicolumn{4}{|c|}{$\begin{array}{l}\pi^{*}=\text { Polarity index }, \beta=\text { hydrogen bond accepting ability, } \alpha=\text { hydrogen bond donating } \\
\text { ability. }\end{array}$} \\
\hline
\end{tabular}

Note SN2. Bagchi and Chatterjee Model for estimation of local mole fraction.

In this model, the observed spectral shifts are ascribed to solvent composition in the solvation shell and inherent solvent-solvent interactions in absence of solute are neglected. In this assumption, in an ideal case, the expected emission peak maxima can be calculated as:

$$
\tilde{v}\left(x_{p}, \text { ideal }\right)=x_{n} \tilde{v}_{n}+x_{p} \tilde{v}_{p}
$$

Where, $x_{n}$ and $x_{p}$ are non-polar and polar component mole fractions and $\tilde{v}_{n}$ and $\tilde{v}_{p}$ their respective emission maxima in neat solvents. However in non-ideal case where PS has occurred, the observed shift $\tilde{v}\left(x_{p}\right)$ is then,

$$
\tilde{v}\left(x_{p}\right)=x_{n}^{L} \tilde{v}_{n}+x_{p}^{L} \tilde{v}_{p}
$$

Where $x_{n}^{L}$ and $x_{p}^{L}$ are the local mole fractions of non-polar and polar solvent component in the solvent mixture. $x_{p}^{L}$ can then be evaluated as,

$$
x_{p}^{L}=\frac{\tilde{v}\left(x_{p}\right)-\tilde{v}_{p}}{\tilde{v}_{p}-\tilde{v}_{n}}
$$


Table ST2. Local mole fractions $x_{p}^{L}$ and deviation from bulk mole fractions $\delta_{p}$ for DEE$\mathrm{ACN} / \mathrm{MeOH}$ solvent mixtures

\begin{tabular}{|c|c|c|c|c|c|c|c|}
\hline \multicolumn{4}{|c|}{ Diethyl ether - Acetonitrile } & \multicolumn{4}{|c|}{ Diethyl ether - Methanol } \\
\hline$x_{p}$ & $\tilde{v}\left(x_{p}\right)$ & $x_{p}^{L}$ & $\delta_{p}$ & $x_{p}$ & $\tilde{v}\left(x_{p}\right)$ & $x_{p}^{L}$ & $\delta_{p}$ \\
\hline 0.0000 & 21645.02 & 0.0000 & 0.0000 & 0.0000 & 21598.27 & 0.0000 & 0.0000 \\
\hline 0.0020 & 21632.02 & 0.0126 & 0.0106 & 0.0026 & 21367.52 & 0.1023 & 0.0997 \\
\hline 0.0040 & 21615.02 & 0.0292 & 0.0253 & 0.0051 & 21231.42 & 0.1626 & 0.1575 \\
\hline 0.0099 & 21598.27 & 0.0455 & 0.0356 & 0.0127 & 21008.40 & 0.2615 & 0.2487 \\
\hline 0.0197 & 21582.27 & 0.0611 & 0.0414 & 0.0253 & 20833.33 & 0.3391 & 0.3138 \\
\hline 0.0390 & 21551.72 & 0.0909 & 0.0519 & 0.0498 & 20576.13 & 0.4531 & 0.4033 \\
\hline 0.0580 & 21505.38 & 0.1360 & 0.0781 & 0.0736 & 20449.90 & 0.5091 & 0.4354 \\
\hline 0.0766 & 21413.28 & 0.2258 & 0.1492 & 0.0967 & 20366.60 & 0.5460 & 0.4493 \\
\hline 0.0948 & 21413.28 & 0.2258 & 0.1309 & 0.1191 & 20202.02 & 0.6189 & 0.4998 \\
\hline 0.1811 & 21321.96 & 0.3147 & 0.1336 & 0.2221 & 20000.00 & 0.7085 & 0.4864 \\
\hline 0.2599 & 21231.42 & 0.4029 & 0.1430 & 0.3911 & 19841.27 & 0.7788 & 0.3877 \\
\hline 0.3989 & 21052.63 & 0.5771 & 0.1783 & 0.5241 & 19723.87 & 0.8309 & 0.3068 \\
\hline 0.4604 & 21008.40 & 0.6202 & 0.1599 & 0.6314 & 19569.47 & 0.8993 & 0.2679 \\
\hline 0.5703 & 20920.50 & 0.7058 & 0.1356 & 0.7199 & 19455.25 & 0.9500 & 0.2301 \\
\hline 0.6656 & 20833.33 & 0.7908 & 0.1252 & 0.8571 & 19417.48 & 0.9667 & 0.1096 \\
\hline 0.7491 & 20790.02 & 0.8330 & 0.0839 & 0.9113 & 19379.84 & 0.9834 & 0.0720 \\
\hline 0.8566 & 20703.93 & 0.9168 & 0.0603 & 0.9586 & 19342.36 & 1.0000 & 0.0414 \\
\hline 1.0000 & 20618.56 & 1.0000 & 0.0000 & 1.0000 & 19342.36 & 1.0000 & 0.0000 \\
\hline
\end{tabular}

Table ST3. Local mole fractions $x_{p}^{L}$ and deviation from bulk mole fractions $\delta_{p}$ for Hexane$\mathrm{EtOH} / \mathrm{tBuOH}$ solvent mixtures

\begin{tabular}{|c|c|c|c|c|c|c|c|}
\hline \multicolumn{4}{|c|}{ Hexane - Ethanol } & \multicolumn{4}{|c|}{ Hexane - tButanol } \\
\hline$x_{p}$ & $\tilde{v}\left(x_{p}\right)$ & $x_{p}^{L}$ & $\delta_{p}$ & $x_{p}$ & $\tilde{v}\left(x_{p}\right)$ & $x_{p}^{L}$ & $\delta_{p}$ \\
\hline 0.0000 & 23809.52 & 0.0000 & 0.0000 & 0.0000 & 23809.52 & 0.0000 & 0.0000 \\
\hline 0.0014 & 22624.43 & 0.2770 & 0.2756 & 0.0022 & 22831.05 & 0.2137 & 0.2115 \\
\hline 0.0027 & 21834.06 & 0.4617 & 0.4590 & 0.0056 & 21739.13 & 0.4522 & 0.4466 \\
\hline 0.0041 & 21505.38 & 0.5386 & 0.5344 & 0.0111 & 21505.38 & 0.5032 & 0.4921 \\
\hline 0.0069 & 21186.44 & 0.6131 & 0.6063 & 0.0221 & 21052.63 & 0.6021 & 0.5800 \\
\hline 0.0137 & 20876.83 & 0.6855 & 0.6718 & 0.0329 & 20833.33 & 0.6500 & 0.6171 \\
\hline 0.0408 & 20618.56 & 0.7459 & 0.7050 & 0.0436 & 20533.88 & 0.7154 & 0.6718 \\
\hline 0.0675 & 20283.98 & 0.8241 & 0.7565 & 0.1053 & 20000.00 & 0.8320 & 0.7267 \\
\hline 0.1326 & 20120.72 & 0.8622 & 0.7296 & 0.1990 & 19723.87 & 0.8923 & 0.6933 \\
\hline 0.2559 & 19960.08 & 0.8998 & 0.6438 & 0.3586 & 19607.84 & 0.9176 & 0.5590 \\
\hline 0.3709 & 19723.87 & 0.9550 & 0.5840 & 0.4894 & 19569.47 & 0.9260 & 0.4366 \\
\hline 0.4784 & 19685.04 & 0.9641 & 0.4856 & 0.5985 & 19455.25 & 0.9510 & 0.3524 \\
\hline 0.5791 & 19646.37 & 0.9731 & 0.3940 & 0.6910 & 19379.84 & 0.9674 & 0.2764 \\
\hline 0.6736 & 19607.84 & 0.9821 & 0.3085 & 0.7704 & 19379.84 & 0.9674 & 0.1971 \\
\hline 0.7625 & 19569.47 & 0.9911 & 0.2286 & 0.8392 & 19342.36 & 0.9756 & 0.1364 \\
\hline 0.8462 & 19531.25 & 1.0000 & 0.1538 & 0.8995 & 19342.36 & 0.9756 & 0.0762 \\
\hline 0.9253 & 19531.25 & 1.0000 & 0.0747 & 0.9527 & 19305.02 & 0.9838 & 0.0311 \\
\hline 1.0000 & 19531.25 & 1.0000 & 0.0000 & 1.0000 & 19230.77 & 1.0000 & -0.0000 \\
\hline
\end{tabular}




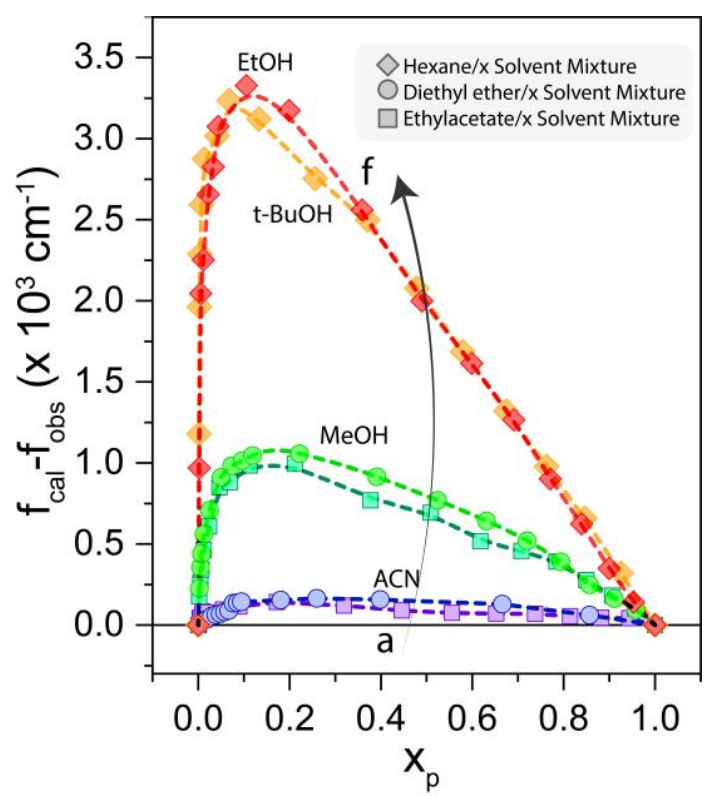

Figure S2. Preferential Solvation from calculated vs experimental emission maxima. Plot of difference in experimental emission maxima and calculated band maxima against mole fraction $x_{p}$ for a) EA-ACN, b) DEE-ACN, c) EA-MeOH, d) DEE-MeOH, e) Hexane$\mathrm{tBuOH}$ and f) Hexane-EtOH solvent mixtures. Area under these curves gives the preferential solvation index $\rho$. 


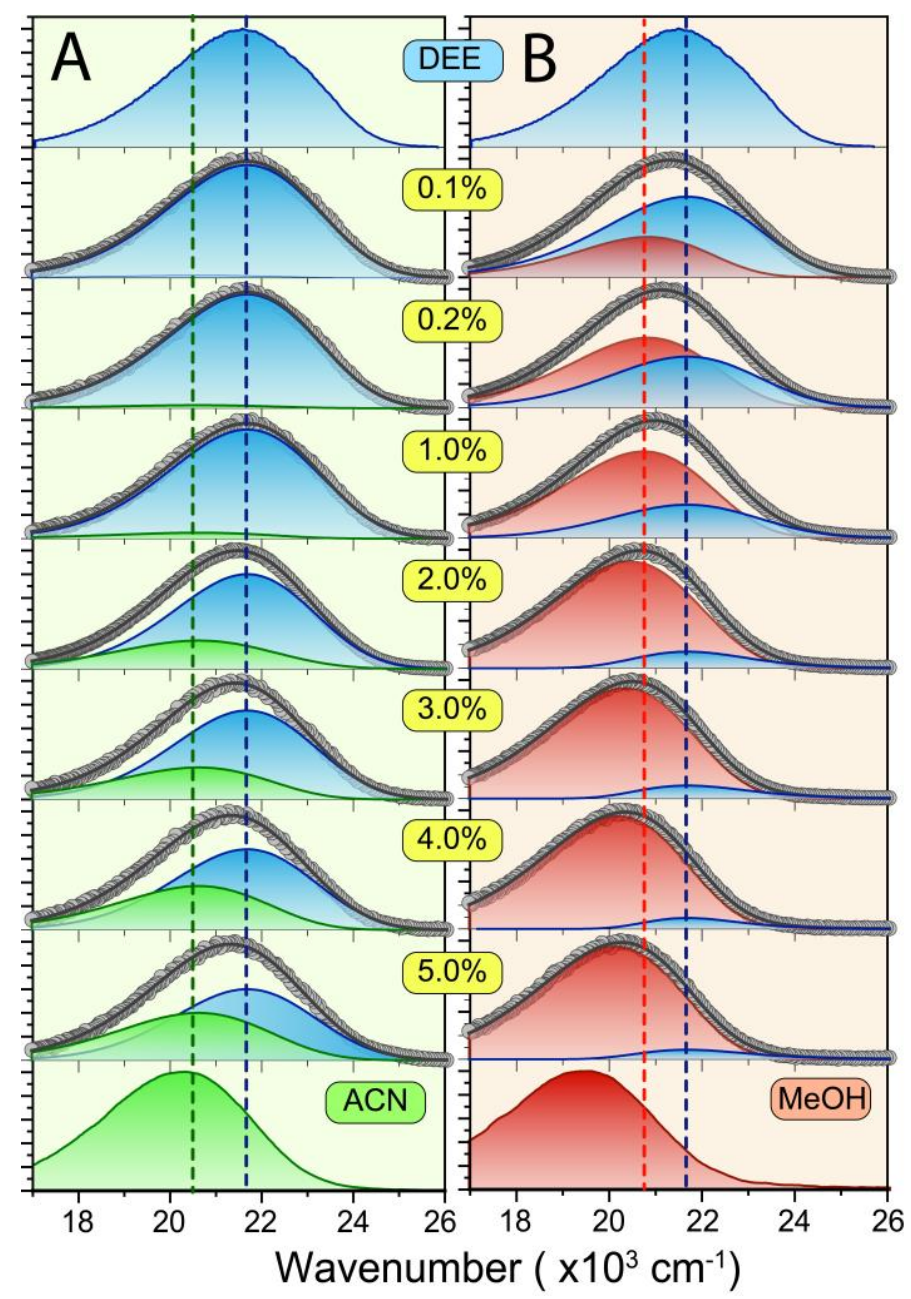

Figure S3. Two-component fits to emission spectra. Steady state fluorescence spectra of 5Aminoquinoline in (A) Diethyl ether - Acetonitrile (left panel) and (B) Diethyl ether Methanol (right panel) solvent mixtures with increasing concentration of polar component $(\% \mathrm{v} / \mathrm{v})$ as indicated. Top and bottom panels in both show emission spectra in neat diethyl ether and methanol respectively. Experimentally recorded emission spectra (circles $\odot$ ) are fitted to sum of two-lognormal functions (fit line is shown in bold line).

Table ST4. Fitting parameters for emission spectra of 5AQ in DEE-ACN and DEE-MeOH solvent mixtures.

\begin{tabular}{|c|c|c|c|c|c|c|c|c|c|c|}
\hline \multirow{2}{*}{$x_{p}$} & \multicolumn{5}{|c|}{ Diethyl ether - Acetonitrile } & \multicolumn{5}{|c|}{ Diethyl ether - Methanol } \\
\hline & $y_{1}$ & $y_{2}$ & $b_{2}$ & $\widetilde{v_{2}}$ & $d_{2}$ & $y_{1}$ & $y_{2}$ & $b_{2}$ & $\widetilde{v_{2}}$ & $d_{2}$ \\
\hline 0 & 0 & 1 & -0.17 & 21682 & 3851 & 0 & 1 & -0.17 & 21682 & 3851 \\
\hline 0.002 & 0.98 & 0.02 & -0.24 & 20618 & 3919 & 0.7 & 0.3 & -0.23 & 20826 & 3383 \\
\hline 0.004 & 0.97 & 0.03 & -0.23 & 20618 & 3773 & 0.43 & 0.57 & -0.22 & 20826 & 3654 \\
\hline 0.01 & 0.93 & 0.07 & -0.24 & 20618 & 3952 & 0.28 & 0.72 & -0.23 & 20745 & 3662 \\
\hline 0.045 & 0.8 & 0.2 & -0.18 & 20618 & 3683 & 0.14 & 0.86 & -0.19 & 20452 & 3686 \\
\hline 0.06 & 0.75 & 0.25 & -0.24 & 20618 & 3909 & 0.11 & 0.89 & -0.2 & 20333 & 3650 \\
\hline 0.086 & 0.68 & 0.32 & -0.22 & 20618 & 3662 & 0.09 & 0.91 & -0.22 & 20197 & 3636 \\
\hline 0.1 & 0.6 & 0.4 & -0.19 & 20618 & 3885 & 0.08 & 0.92 & -0.22 & 20132 & 3650 \\
\hline
\end{tabular}



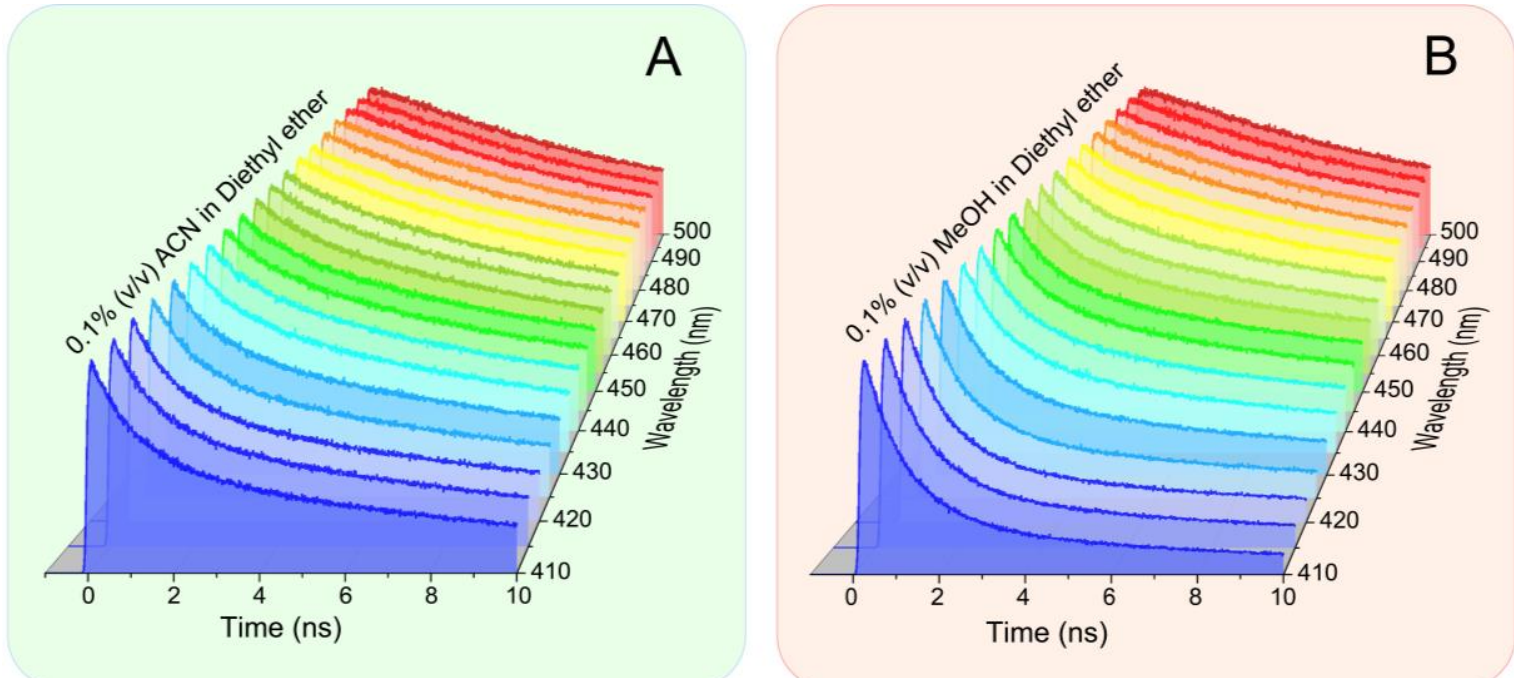

Figure S4. Wavelength dependence of fluorescence transients. Fluorescence decays of 5AQ in A) $0.1 \%(\mathrm{v} / \mathrm{v})$ DEE-ACN solvent mixture and B) $0.1 \%(\mathrm{v} / \mathrm{v}) \mathrm{DEE}-\mathrm{MeOH}$ solvent mixture using $\lambda_{\text {exc }}=375 \mathrm{~nm}$ and $\lambda_{\text {ems }}=410 \mathrm{~nm}$ to $500 \mathrm{~nm}$ at $5 \mathrm{~nm}$ intervals.

Table ST5. Fitting parameters for TCSPC transients of 5AQ at various DEE-ACN solvent mixture composition.

\begin{tabular}{|c|c|c|c|c|c|c|c|c|}
\hline & \multicolumn{4}{|c|}{$\lambda_{e m}^{m a x}=420 \mathrm{~nm}$} & \multicolumn{4}{|c|}{$\lambda_{e m}^{\max }=550 \mathrm{~nm}$} \\
\hline & $\tau_{1}$ & $a_{1}$ & $\tau_{2}$ & $a_{2}$ & $\tau_{1}$ & $a_{1}$ & $\tau_{2}$ & $a_{2}$ \\
\hline$\overline{\mathbf{0}}$ & & & 14.1 & & & & 14.3 & \\
\hline $10 \%$ & 1.5 & 0.07 & 11.838 & 0.930 & 0.35 & -0.24 & 11.58 & 1.24 \\
\hline $20 \%$ & 1.3 & 0.08 & 11.907 & 0.916 & 0.41 & -0.159 & 11.76 & 1.159 \\
\hline $30 \%$ & 1.4 & 0.085 & 12.316 & 0.934 & 0.42 & -0.235 & 12.02 & 1.235 \\
\hline $40 \%$ & 1.45 & 0.11 & 12.457 & 0.927 & 0.44 & -0.239 & 12.23 & 1.239 \\
\hline $50 \%$ & 1.33 & 0.19 & 12.615 & 0.940 & 0.51 & -0.249 & 12.35 & 1.249 \\
\hline $60 \%$ & 1.25 & 0.25 & 15.207 & 0.930 & 0.48 & -0.185 & 12.45 & 1.185 \\
\hline $70 \%$ & 1.2 & 0.17 & 15.980 & 0.144 & 0.45 & -0.129 & 12.47 & 1.129 \\
\hline $80 \%$ & 1.14 & 0.11 & 12.731 & 0.508 & 0.42 & -0.128 & 12.45 & 1.128 \\
\hline $90 \%$ & 1.15 & 0.07 & 14.874 & 0.922 & 0.39 & -0.118 & 12.41 & 1.118 \\
\hline $100 \%$ & & & 12.46 & & & & 12.51 & \\
\hline
\end{tabular}


Table ST6. Fitting parameters for TCSPC transients of 5AQ at various DEE-MeOH solvent mixture composition.

\begin{tabular}{|c|c|c|c|c|c|c|c|c|}
\hline & \multicolumn{4}{|c|}{$\lambda_{e m}^{\max }=420 \mathrm{~nm}$} & \multicolumn{4}{|c|}{$\lambda_{e m}^{\max }=550 \mathrm{~nm}$} \\
\hline & $\tau_{1}$ & $a_{1}$ & $\tau_{2}$ & $a_{2}$ & $\tau_{1}$ & $a_{1}$ & $\tau_{2}$ & $a_{2}$ \\
\hline 0 & & & 14.2 & & & & 14.4 & \\
\hline $0.1 \%$ & 1.1 & 0.2 & 11.60 & 0.8 & 1.3 & -0.21 & 12.7 & 1.21 \\
\hline $0.2 \%$ & 0.91 & 0.23 & 11.42 & 0.77 & 0.73 & -0.26 & 11.5 & 1.26 \\
\hline $0.3 \%$ & 0.83 & 0.4 & 10.05 & 0.6 & 0.64 & -0.32 & 10.8 & 1.32 \\
\hline $0.5 \%$ & 0.7 & 0.34 & 9.5 & 0.66 & 0.55 & -0.39 & 10.3 & 1.39 \\
\hline $1.0 \%$ & 0.5 & 0.45 & 9.1 & 0.55 & 0.4 & -0.65 & 8.6 & 1.65 \\
\hline $2.0 \%$ & 0.47 & 0.5 & 8.8 & 0.5 & 0.38 & -0.69 & 8.6 & 1.69 \\
\hline $3.0 \%$ & 0.38 & 0.61 & 7.2 & 0.49 & 0.37 & -0.72 & 7.1 & 1.72 \\
\hline $4.0 \%$ & 0.3 & 0.66 & 6.5 & 0.34 & 0.32 & -0.74 & 6.6 & 1.74 \\
\hline $5.0 \%$ & 0.2 & 0.7 & 3.1 & 0.3 & 0.28 & -0.77 & 3.0 & 1.77 \\
\hline $10.0 \%$ & - & - & 1.2 & 1 & 0.25 & -0.8 & 1.4 & 1.8 \\
\hline
\end{tabular}

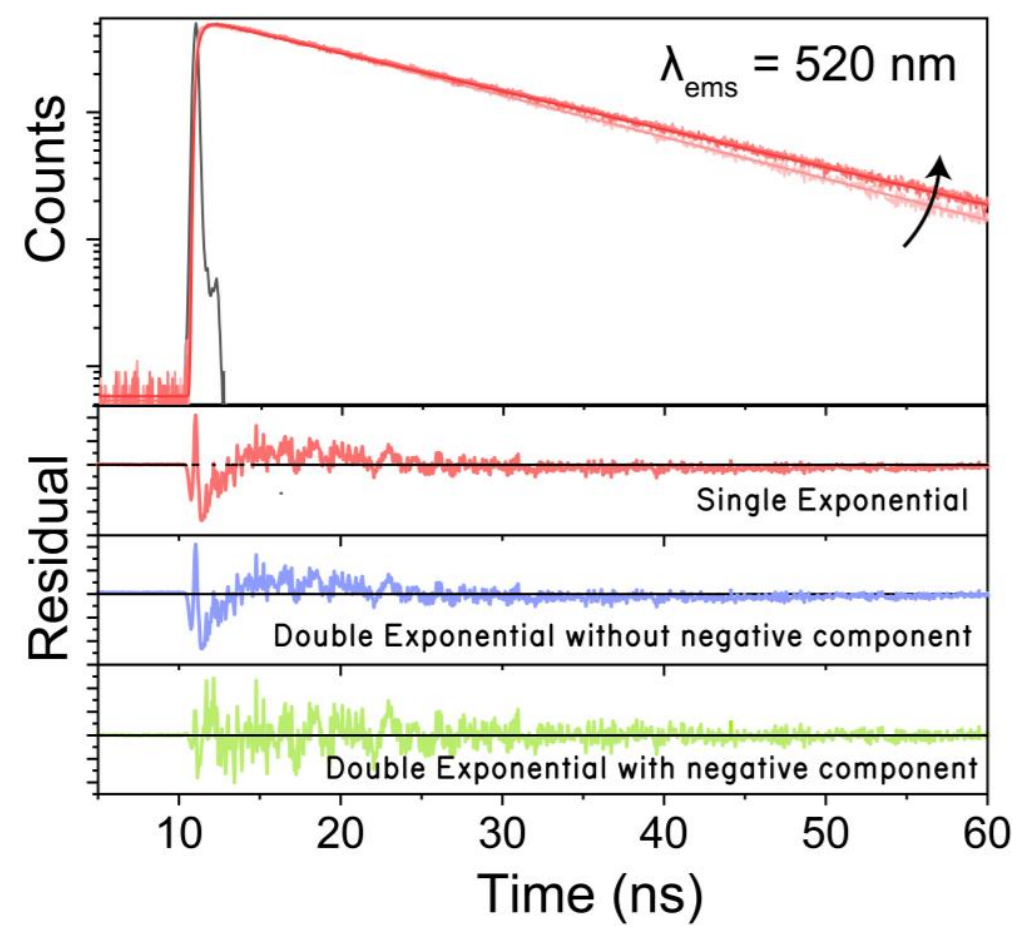

Figure S5. Rise time observed at red end of TCSPC transients. As seen from the residuals, best fit is only obtained with a negative (rise) component. 


\section{Note SN3. Estimation of translational diffusion timescales.}

For cases of preferential solvation or dielectric enrichment resulting from diffusion controlled solvation of probe by polar solvent molecules in the bulk, Suppan and co-workers have defined a model for estimation of timescales of translational diffusion ${ }^{1}$ defined by,

$$
t=\frac{\left(x_{p}^{L}-x_{p}\right) \pi M a^{2}}{k_{D} x_{p} 10^{3} \delta b^{2}}
$$

Where, $x_{p}^{L}$ and $x_{p}$ are local and bulk mole fractions of the polar component, $M$ and $\delta$ are mean molecular weight and density of solvents, $a$ and $b$ mean molecular radii of solute and solvent, $k_{D}$ rate constant for diffusion controlled solute-solvent interaction. In very dilute solutions w.r.t. polar solvent component, this timescale is of the order of a few nanoseconds.

Smoluchowski theory ${ }^{2}$ defines diffusion controlled rate constant as,

$$
k_{D}=\frac{4 \pi R D N_{A}}{1000}
$$

where $k_{D}$ is the diffusion controlled rate constant in $\mathrm{M}^{-1} \mathrm{~s}^{-1}, R$ is the encounter distance in cm, $D$ is the translational diffusion coefficient in $\mathrm{cm}^{2} \mathrm{~s}^{-1}$, and $N_{A}$ is the Avogadro constant. As solvation of $5 \mathrm{AQ}$ in DEE-MeOH solvent mixtures involves translational diffusion of $\mathrm{MeOH}$ molecules from bulk to the solvation shell, the closest approximation of diffusion coefficient is that of $\mathrm{MeOH}$ in hexane (considering similar viscosity of DEE- and hexane-0.224) which is $1.96 \times 10^{-5} \mathrm{~cm}^{2} \mathrm{~s}^{-1}$ at $x_{p} \sim 0.05 .{ }^{3}$ The encounter distance $\mathrm{R}$ is approximated by the thickness of the solvation shell $\left(\sim 5.7 \times 10^{-8} \mathrm{~cm}\right.$, considering average length of $\mathrm{MeOH}$ and DEE molecules). These values give, $k_{D}=8.55 \times 10^{9} \mathrm{M}^{-1} \mathrm{~s}^{-1}$. Using, $x_{p}, x_{p}^{L}$ (estimated using Bagchi-Chatterjee Model, Table ST2, SI), above calculated $k_{D}$, typical value of $a^{2} / b^{2}=2$ and solvent component properties which gives $M=53.08 \mathrm{~g} \mathrm{~mol}^{-1}, \delta=0.7525 \mathrm{~g} \mathrm{~mL}^{-1}$, gives translational diffusion timescales $t_{\text {cal }}$ listed below.

Table ST7. Calculated translational diffusion times in various concentration of DEE-MeOH

\begin{tabular}{|c|c|c|c|c|c|}
\hline $\begin{array}{c}\text { Conc } \\
(\% \\
\mathrm{v} / \mathrm{v}) \\
\end{array}$ & $x_{p}$ & $x_{p}^{L}$ & $\begin{array}{l}t_{c a l} \\
(\mathrm{~ns})\end{array}$ & $\begin{array}{c}\boldsymbol{t}_{\text {exp }}(\mathbf{n s})\left[\tau_{3} \text { at } \lambda_{\text {em }}=550 \mathrm{~nm},\right. \\
\text { Table 3] }\end{array}$ & $x(\mathrm{~nm})$ \\
\hline $0.1 \%$ & 0.0026 & 0.0997 & 1.84 & 1.3 & 2.2 \\
\hline $0.5 \%$ & 0.0127 & 0.2487 & 0.91 & 0.6 & 1.5 \\
\hline $1.0 \%$ & 0.0253 & 0.3138 & 0.56 & 0.4 & 1.2 \\
\hline $10 \%$ & 0.2221 & 0.4864 & 0.06 & 0.25 & 0.96 \\
\hline
\end{tabular}
solvent mixture.

The reduction in diffusion time is consistent with a translational diffusion model as has been estimated using the model by Suppan and co-workers, as listed in the table above. The mean distance travelled in a given time can be estimated from, 


$$
t=\frac{x^{2}}{2 D}
$$

where, $D=$ diffusion coefficient, $x$ is distance travelled in time $t$. Using $D=1.96 \times 10^{-9} \mathrm{~m}^{2} \mathrm{~s}^{-1}$ for $\mathrm{MeOH}$ in hexane and corresponding rise time $t=1.3 \mathrm{~ns}$ (at $x_{p}=0.0026 \mathrm{MeOH}$ in DEE), $x$ is calculated as $2.2 \mathrm{~nm}$ (Table ST7). Considering length of DEE molecule $(\sim 0.8 \mathrm{~nm})$ this corresponds to $\sim 3$ solvation layers. While this value is a little large, it can be rationalized considering the extremely small mole fraction of $\mathrm{MeOH}$ in DEE and that the solvation is a translational diffusion controlled encounter of solute-solvent. We have included this discussion in SI of the revised manuscript. 


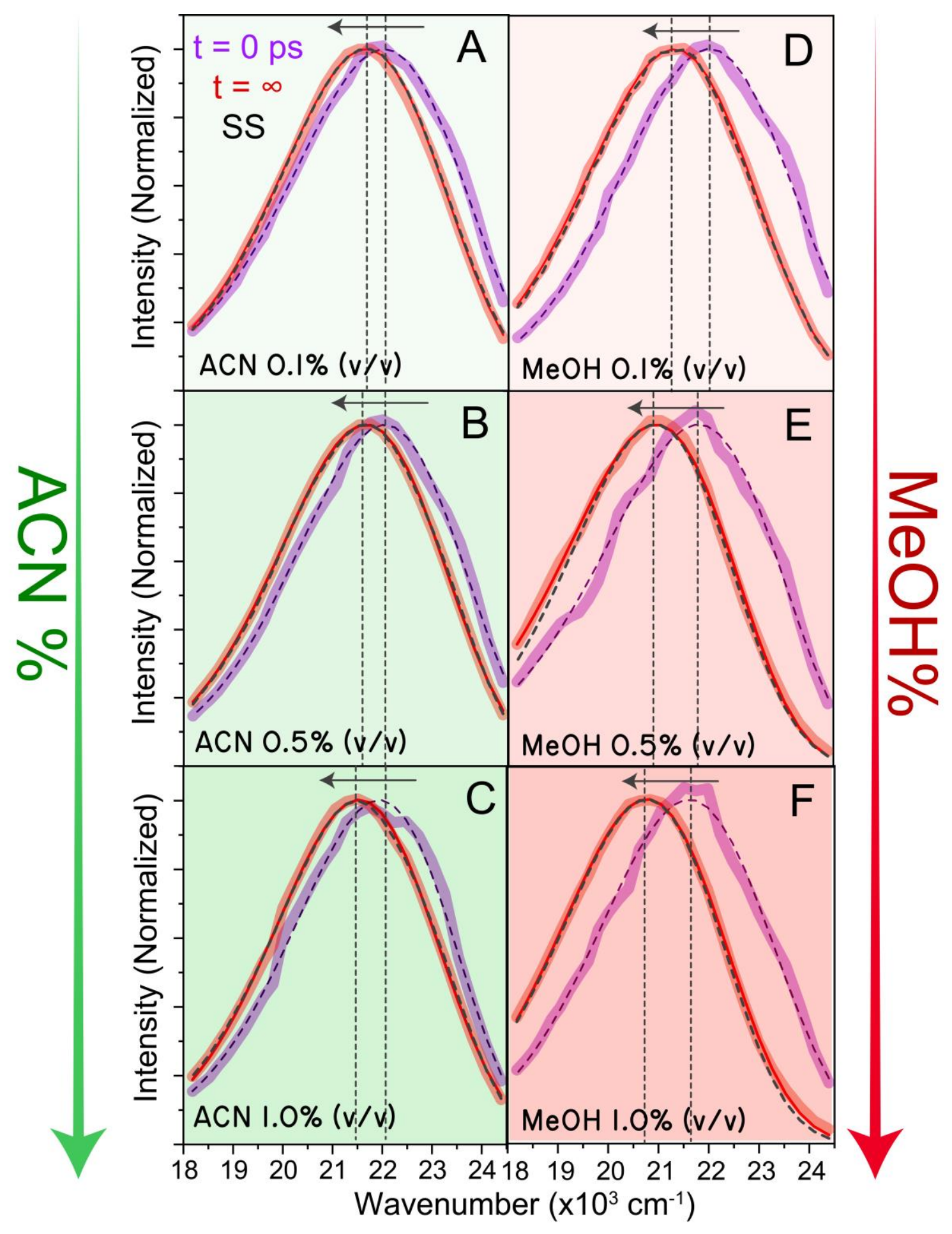

Figure S6. Time resolved emission spectra (TRES). Normalized TRES of 5AQ in DEE$\mathrm{ACN}$ solvent mixture (A, B, C) and DEE-MeOH solvent mixture (D, E, F). Concentration of the polar component in the solvent mixture is as indicated. The dashed blue and red lines represent the corresponding fit to the raw TRES spectra and dashed black line is the steady state spectra for as indicated solvent mixture concentration. 

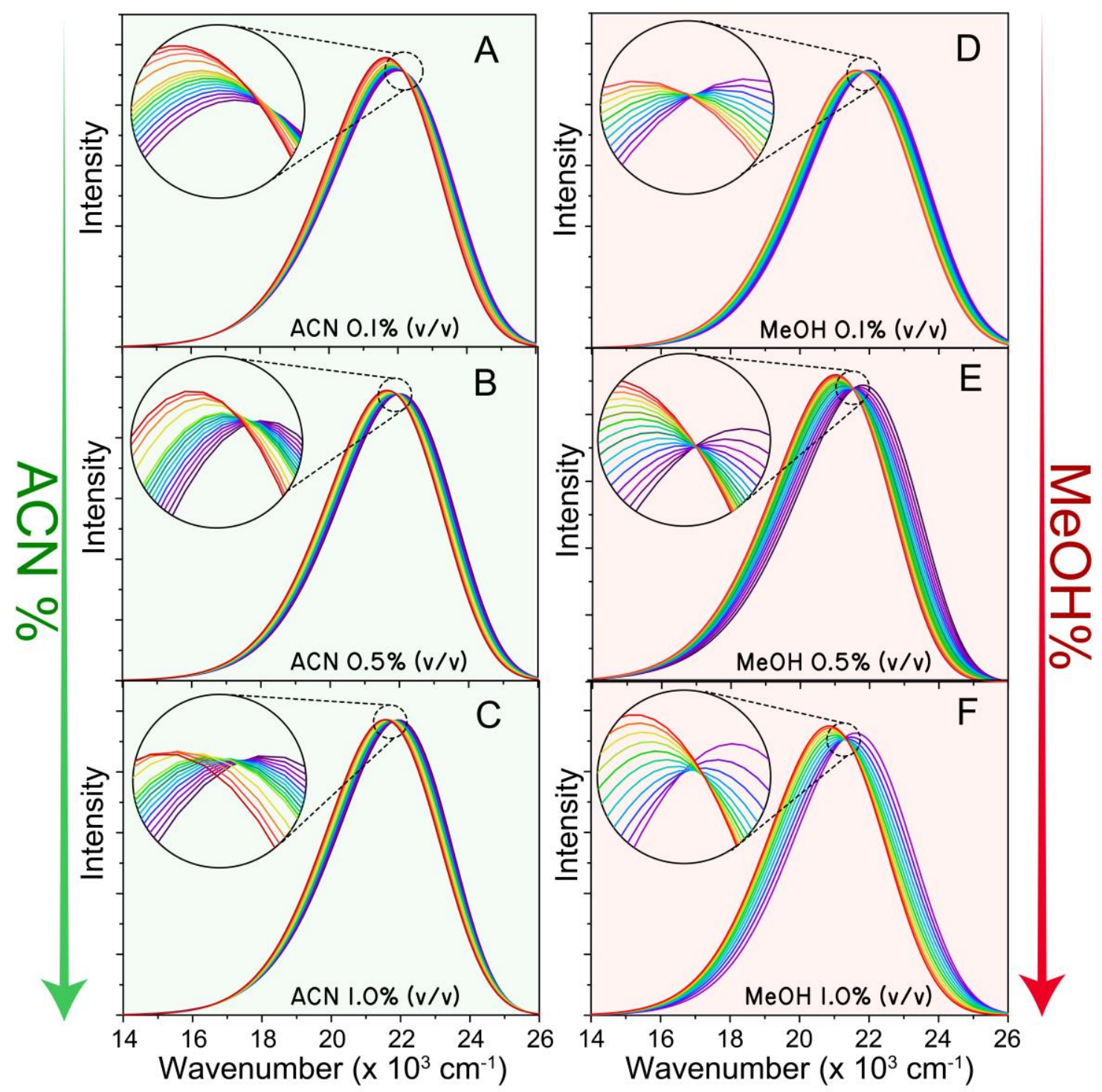

Figure S7. Time resolved area normalised emission spectra (TRANES). TRANES of 5AQ in DEE-ACN solvent mixture (A, B, C) and DEE-MeOH solvent mixture (D, E, F). Concentration of the polar component in the solvent mixture is as indicated. 

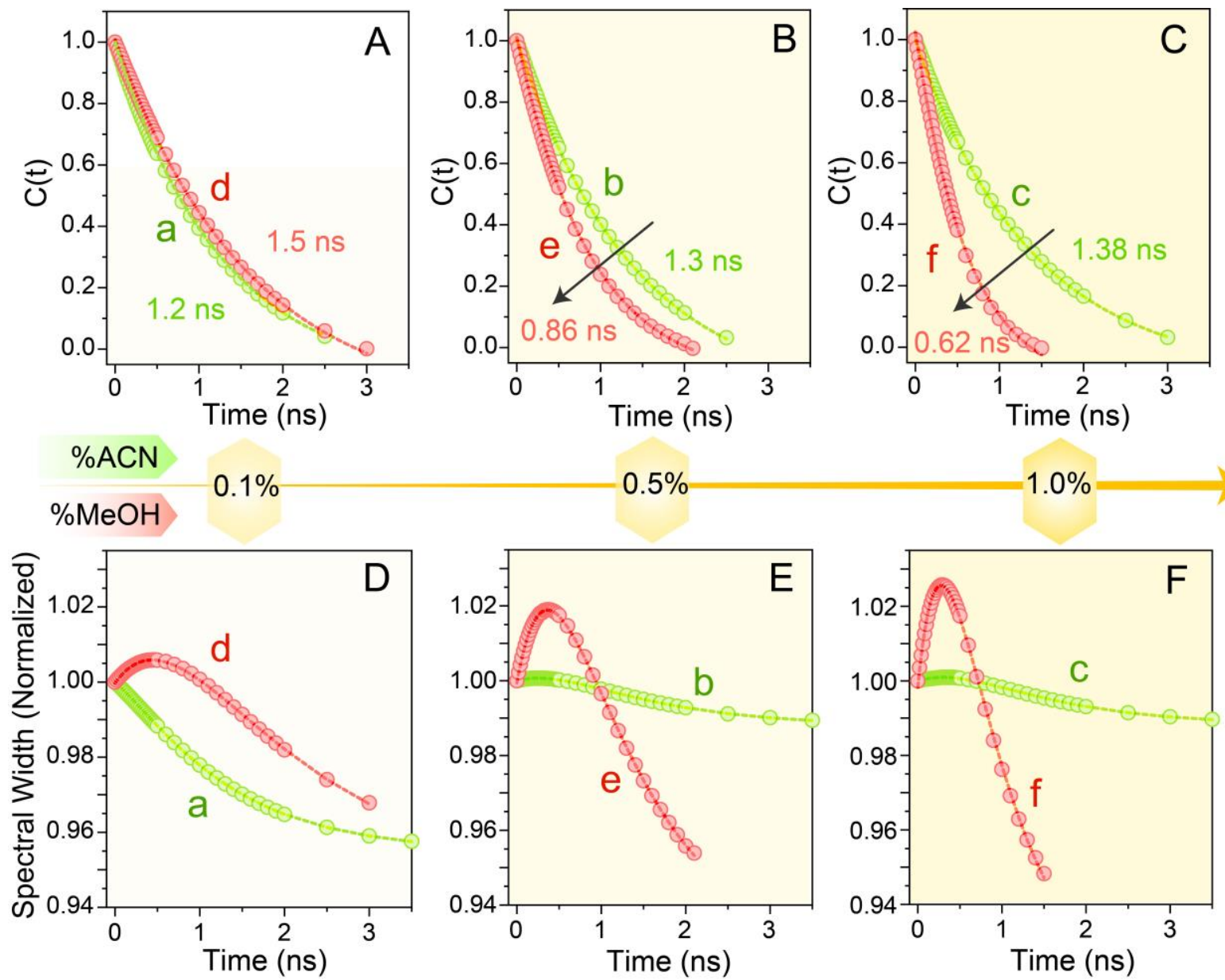

Figure S8. C(t) and FWHM variation. Variation of $(\mathrm{A}, \mathrm{B}, \mathrm{C}) \mathrm{C}(\mathrm{t})$ and $(\mathrm{D}, \mathrm{E}, \mathrm{F})$ time evolution of FWHM of TRES of 5AQ in various concentrations of DEE-ACN (curves a, b, c) and DEE-MeOH (curves d, e, f) solvent mixtures. 

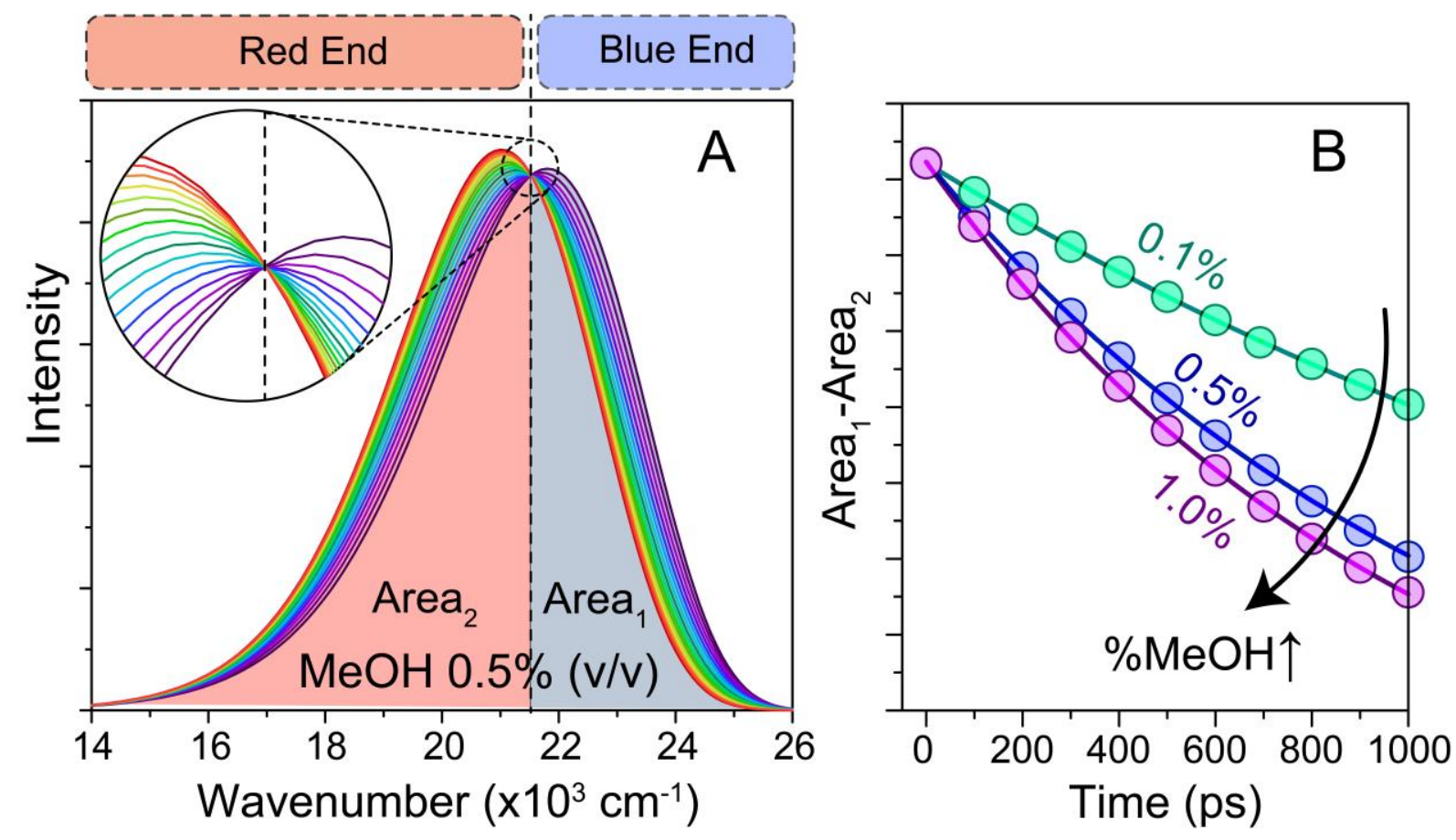

Figure S9. TRANES analysis. A) Method for estimating the time constant for estimating the second state from difference in area under the curve of blue end and red end with iso-emissive point as the reference point (Area ${ }_{1}$ Area $_{2}$ as indicated). B) Variation of area difference Area $1^{-}$ $\mathrm{Area}_{2}$ with delay time, at different concentrations of $\mathrm{MeOH}$ in $\mathrm{DEE}-\mathrm{MeOH}$ solvent mixtures. 